\title{
Erratum: Time-Reversed Dynamical Entropy and Irreversibility in Markovian Random Processes ${ }^{1}$
}

\author{
Pierre Gaspard ${ }^{2}$
}

Received July 25, 2006; accepted August 15, 2006

Published Online: November 10, 2006

Dr. Mitsusada M. Sano of Kyoto University has kindly pointed out to the Author that Eq. (21) for the entropy flow should read:

$$
\Delta_{\mathrm{e}} S_{t} \equiv-\sum_{\omega \omega^{\prime}} p_{t}(\omega) P\left(\omega \mid \omega^{\prime}\right) \ln \frac{p_{t+1}\left(\omega^{\prime}\right) P\left(\omega \mid \omega^{\prime}\right)}{p_{t}\left(\omega^{\prime}\right) P\left(\omega^{\prime} \mid \omega\right)}
$$

\footnotetext{
${ }_{1}^{1}$ Journal of Statistical Physics 117, 599-615 (2004), DOI: 10.1007/s10955-004-3455-1.

${ }^{2}$ Center for Nonlinear Phenomena and Complex Systems, Université Libre de Bruxelles, Brussels, Belgium.
} 